This is the author's final, peer-reviewed manuscript as accepted for publication. The publisher-formatted version may be available through the publisher's web site or your institution's library.

\title{
Septate endophyte colonization and host responses of grasses and forbs native to a tallgrass prairie
}

Keerthi Mandyam; Chad Fox; Ari Jumpponen

\section{How to cite this manuscript}

If you make reference to this version of the manuscript, use the following information:

Mandyam, K., Fox, C., \& Jumpponen, A. (2012). Septate endophyte colonization and host responses of grasses and forbs native to a tallgrass prairie. Retrieved from http://krex.ksu.edu

\section{Published Version Information}

Citation: Mandyam, K., Fox, C., \& Jumpponen, A. (2012). Septate endophyte colonization and host responses of grasses and forbs native to a tallgrass prairie. Mycorrhiza, 22(2), 109-119.

Copyright: Copyright Springer-Verlag 2011

Digital Object Identifier (DOI): doi: 10.1007/s00572-011-0386-y

Publisher's Link: http://www.springerlink.com/content/j528462405217407/ 


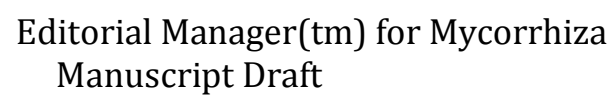

Manuscript Number: MCOR-D-11-00032R1

Title: Septate endophyte colonization and host responses of grasses and forbs native to a tallgrass prairie

Article Type: Original Paper

Keywords: Dark septate endophytes (DSE), mycorrhizal dependency, mutualism-parasitism continuum

Corresponding Author: Ari Jumpponen

Corresponding Author's Institution: Kansas State University

First Author: Keerthi Mandyam, M.Sc., Ph.D.

Order of Authors: Keerthi Mandyam, M.Sc., Ph.D.;Chad Fox;Ari Jumpponen

Abstract: Native tallgrass prairies support distinct dark septate endophyte (DSE) communities exemplified by Periconia macrospinosa and Microdochium sp. that were recently identified as common root-symbionts in this system. Since these DSE fungi were repeatedly isolated from grasses and forbs, we aimed to test their abilities to colonize different hosts. One Microdochium and three Periconia strains were screened for colonization and growth responses using five native grasses and six forbs in an in vitro system. Previously published data for an additional grass (Andropogon gerardii) were included and reanalyzed. Presence of indicative inter- and intracellular structures (melanized hyphae, microsclerotia and chlamydospores) demonstrated that all plant species were colonized by the DSE isolates albeit to varying degrees. Microscopic observations suggested that, compared to forbs, grasses were colonized to a greater degree in vitro. Host biomass responses varied among the host species. In broad comparisons, more grass species than forbs tended to respond positively to colonization, whereas more forb species tended to be non-responsive. Based on the suspected differences in the levels of colonization, we predicted that tallgrass prairie grasses would support greater DSE colonization than forbs in the field. A survey of field-collected roots from fifteen native species supported this hypothesis. Our study supports the 'broad host range' of DSE fungi, although the differences in the rates of colonization in the laboratory and in the field suggest a greater compatibility between grasses and DSE fungi. Furthermore, host responses to DSE range from mutualism to parasitism, suggesting a genotype-level interplay between the fungi and their hosts that determines the outcome of this symbiosis. 
Response to reviewers

Reviewer \#1:

As per reviewer's request, we have omitted references to "host preferences" throughout the manuscript. Additionally, we have followed the reviewer's recommendations on issues relating to "visual, susceptible, arcsine of the square root, vascular cylinder,...." as well as made all minor editorial changes requested.

The reviewer requests further details on our Microdochium isolate. We believe that those details are adequately available in Mandyam et al. (2010) and wish to avoid unnecessary duplication of results.

The reviewer wonders about the authorities for fungal names. We are a bit in a loss with this comment since we believe our authorities being correctly used. Please advise.

We have revised the sentence in lines 82-85. This section now reads: "Recent metaanalyses of the limited number of available studies have produced conflicting results. Alberton et al. (2010) concluded that, while host growth responses to DSE fungi were variable, they tended to be on average negative. In contrast, Newsham (2011) found that DSE inoculation tended to increase host biomass, particularly when inoculation was conducted either in a system with no additional inorganic $N$ or when majority of the $N$ had been supplied in organic forms. These conflicting meta-analyses emphasize the considerable variability in host responses to DSE fungi but also that, like arbuscular mycorrhizas and ectomycorrhizas, the DSE symbioses may be contextdependent (Karst et al. 2008; Hoeksema et al. 2010)."

We have revised lines 87-91. This section now reads: "In addition to the inter-and intraspecific variability of the plants (Piculell et al. 2008; Karst et al. 2009) and fungi (Munkvold et al. 2004) addressed here, the differences in host responses may be attributable environmental conditions and modulated by shade, drought, salinity and nutrient depletion (Johnson et al. 1997; Kageyama et al. 2008; Rodriguez et al. 2008; Hoeksema et al. 2010)." 
The reviewer requests further analyses to contrast annuals and perennials. There are only three annuals in the list of species that we included in our field survey: Ambrosia artemisiifolia, Sphaeralcea sp. and Plantago patagonica. We omitted Sphaeralcea from these analyses because of the uncertainty of its perennial or annual habits. Our results suggest that the differences are few, but that the colonization of annual forbs by DSE is delayed compared to perennial forbs. We have incorporated these into our results as well as address them briefly in our discussion.

We agree with the reviewer that resynthesis may not be the best word to describe inoculation assays. However, as the reviewer also points out, this term is quite well established for studies of this kind. This being the case, we are reluctant to look for cumbersome alternatives for the term. Instead we follow the reviewer's request for a brief definition: “...One Microdochium sp. (KS0012) and three Periconia macrospinosa strains (KS0019, KS0045 and KS0100) previously isolated and identified by Mandyam et al. (2010) from KPBS were used for in vitro experiments. In these laboratory experiments, we tested the fungal compatibility with native prairie plants by resynthesizing fungal structures (microsclerotia and chlamydospores, Mandyam et al. 2010) indicative of the DSE symbiosis."

The reviewer's comment on the surface sterilization (1.133) is somewhat inconsequential and perhaps stems from foliar endophyte studies. Since our plants grow in a sterile system with a sterile medium, any mycelium beyond that introduced by us in the resynthesis is considered a contamination. Therefore, we considered it unnecessary to separately confirm the removal of the surface-borne contaminants.

We believe that the statements on 1. 152-153 are explicit and transparent: "...shoots of all 15 replicates and roots of 10 replicates were harvested, dried at $50^{\circ} \mathrm{C}$ and their dry weight recorded. Roots from the remaining five replicates were used for microscopic observation to confirm colonization..." Our point is that we used the whole plant for 10 replicate shoots plus an additional 5 from which the roots were separated for microscopic analyses. The roots of 5 of the 15 replicates were reserved for microscopic analyses.

The reviewer picks our mistake on line 186. These data are skewed, but transformations are not necessary because calculating $\mathrm{R}$ will both normalize and standardize these data so that the values range from - 1 to 1 and centered around zero. We have clarified this point also following the second reviewer's recommendations. 
We have omitted the statement referring to Poa pratensis on line 201.

L. 210. Actually, we did do the initial root cleaning in the field station. We have modified the methods section to more accurately outline this.

L. 214. Autoclaving with $\mathrm{KOH}$ is somewhat of a standard for root clearing since Philips and Hayman (1970). Therefore, we question whether more detail on the clearing is necessary. We do, however, now clarify that it is indeed $5 \mathrm{~min}$ in the $121^{\circ} \mathrm{C}$ and the heating and depressurization are in addition to that time.

L. 219. We now include the ingredients (500ml glycerol, $450 \mathrm{ml} \mathrm{H}_{2} \mathrm{O}, 50 \mathrm{ml} \mathrm{HCl}$ ) for the acidic glycerol to avoid any confusion.

L. 234 and 235-247. We now explicitly state which values were transformed to equalize the variances or to remove violations of ANOVA assumptions. We agree with the reviewer that the Bonferroni correction may be in place. To leave the final decision to use either corrected or uncorrected levels of significance, we provide both in Fig. 2 but discuss only the more conservative Bonferroni adjusted values.

L. 267-270. We removed the vague statement from the beginning of the paragraph but retain the rest of blah blah to keep our reviewer longing for margaritas/coffee.

L. 274. We clarified the awkward sentence and made it to be more to the point. It now reads: "Inoculation with all four fungal strains increased B. gracilis total biomass (221.8\% - 325.0\%) and root biomass (291.1\% - 460.5\%) compared to the fungus-free control; these biomass responses did not alter the root:shoot ratios."

L. 301. We believe that our discussion on the responses is preferable to reviewer's proposal. While we list the positive and negative responses where appropriate, it is indeed the point that forb growth is neither enhanced nor inhibited. In contrast, we have examples of both in grasses. 
L. 342-345. We omitted the call for incorporating the seasonal components into future studies here. However, we wish to retain the statement that indicates that the field and in vitro data agree. We believe that this is a necessary validation - perhaps even a unique one - of the numerous laboratory studies that utilize these highly simplified and derived systems.

L. 374-378. We agree. The justification for the use of responsiveness is better placed in the materials where " $\mathrm{R}$ " is first introduced.

L. 419-423. We modified this section to get to the point. We omitted the details of Tanaka's and Redman's and colleagues studies and jump directly to pointing out that it is indeed environmental and host/fungus genotypic differences and environmental conditions that determine the outcomes of symbiotic interactions.

L. 580-581. We did not detect any differences in the root:shoot ratios. Reviewer is absolutely correct. However, the question remains open whether this is an outcome of the reduced statistical power in those analyses (we had only 10 experimental units for the root masses). We doubt this, but it makes one wonder nonetheless.

L. 583. Four strains indeed, corrected as requested.

Fig. 1. We understand reviewer's concerns. However, we prefer to retain the asterisks to avoid audience confusion. Use of lettering would perhaps be interpreted as pairwise comparisons as in Tukey's and Duncan's tests. Instead, we used Dunnett that explicitly tests treatment differences against a pre-assigned control. Therefore, we see it far more appropriate to use the asterisks.

Reviewer \#2.

Title: We omitted dark from the title initially since Microdochium, while producing dark chlamydospores, does not possess melanized hyphae. We do understand that we use DSE through the manuscript, but wish to be more inclusive than exclusive in the title. 
Abstract: While the percent changes in the biomasses would be desirable indeed, including these data into the abstract would require that we list each of the species and their responses. Therefore including these data without separation to a species level would be difficult here - we provide these details in the results section though.

Introduction: We have followed the reviewer's recommendations to a limited extent. We wish to include Alberton et al. (2010) as it - when contrasted with Newsham's more recent work (2011) - exemplifies the debate and controversy surrounding the host responses to DSE fungi. While we may agree with the arguments presented in Newsham (2011) and by the reviewer, we believe that it may be better to leave stringent criticisms of Alberton's and colleagues work to Newsham's published work.

Materials and Methods:

L. 123-124: Instead of repeating work described elsewhere (Mandyam et al. 2010), we cite this as a source of information for isolation and identification protocols.

L. 170-184: The reviewer's point on the response ratio is a very valid one. However, we prefer our responsiveness $(R)$ because it normalizes and standardizes skewed data. Our materials and methods clearly describe this argument. To exemplify and to beat on a dead horse from our perspective, consider a situation where control plant either does not survive or performs extremely poorly (as with our Bouteloua gracilis) and the response ratio values - even after logarithmic transformation reach exuberantly high values approaching infinity. To eliminate the reviewer's concerns (reference to Fig. 2) about the interpretation of this metric, we now explicitly state: "This metric also simply illustrates the host responses to inoculation: values greater than zero indicate positive responses, values lesser than zero negative responses."

Results:

L.270-280; 325-338: We now include percent-wise effect sizes for the broad groupings as requested.

L. 339-345: We have omitted the discussion from the results but wish to emphasize that the field and laboratory studies support each other.

Discussion: 
L. 405: Corrected as suggested by the reviewer. We also take the reviewer's point about Newsham (2011) to heart. However, instead of including the reference of similarities between our conclusions on grass responsiveness here, we refer to those conclusions in the beginning of our discussion.

L. 416-440: The effect of inorganic $\mathrm{N}$ supply is an excellent point. We have incorporated this thought in the discussion: "An interesting but yet unanswered question is whether or not our results represent an in vitro bias or artefact, even though the overall greater grass compatibility was observed both under the field and in vitro conditions. Newsham (2011) concluded that hosts respond more positively if no inorganic nitrogen is made available in the experiments and when nitrogen is supplied in organic forms. At this point, further experiments are necessary to empirically confirm the conclusions of those meta-analyses. However, our choice to use MS medium with exclusively organic nitrogen sources may have affected the host responses. If this were true and if inorganic nitrogen supply lead to lesser or fewer positive host responses, then we would have underestimated the proportion of the positive host responses. This underestimation may have been further exaggerated by our use of conservative Bonferroni corrections in the analyses of host responsiveness (Fig. 2)."

Figures: We have modified the figures as requested by the reviewer. In brief, Fig. 1 now shows root biomass below and shoot biomass above $\mathrm{x}$-axis and the font sizes and axis labeling to improve clarity; Fig. 2 includes a label for $\mathrm{x}$-axis; all figures identify the grasses by underlining. 
1 Septate endophyte colonization and host responses of grasses and forbs native to a

2 tallgrass prairie

3 Keerthi Mandyam, Chad Fox, Ari Jumpponen*

4 Division of Biology, Kansas State University, Manhattan, KS, 66506, USA

5 *Corresponding author: Ari Jumpponen

6

Division of Biology

Kansas State University

Manhattan, KS 66506

9

USA

Tel. 17855326251

11

Fax 17855326653

12

ari@ksu.edu

13 


\section{Abstract}

15 Native tallgrass prairies support distinct dark septate endophyte (DSE) communities

16 exemplified by Periconia macrospinosa and Microdochium sp. that were recently

17 identified as common root-symbionts in this system. Since these DSE fungi were

18 repeatedly isolated from grasses and forbs, we aimed to test their abilities to colonize

19 different hosts. One Microdochium and three Periconia strains were screened for

20 colonization and growth responses using five native grasses and six forbs in an in vitro

21 system. Previously published data for an additional grass (Andropogon gerardii) were

22 included and reanalyzed. Presence of indicative inter- and intracellular structures

23 (melanized hyphae, microsclerotia and chlamydospores) demonstrated that all plant

24 species were colonized by the DSE isolates albeit to varying degrees. Microscopic

25 observations suggested that, compared to forbs, grasses were colonized to a greater

26 degree in vitro. Host biomass responses varied among the host species. In broad

27 comparisons, more grass species than forbs tended to respond positively to colonization,

28 whereas more forb species tended to be non-responsive. Based on the suspected

29 differences in the levels of colonization, we predicted that tallgrass prairie grasses would

30 support greater DSE colonization than forbs in the field. A survey of field-collected roots

31 from fifteen native species supported this hypothesis. Our study supports the "broad host

32 range' of DSE fungi, although the differences in the rates of colonization in the

33 laboratory and in the field suggest a greater compatibility between grasses and DSE

34 fungi. Furthermore, host responses to DSE range from mutualism to parasitism,

35 suggesting a genotype-level interplay between the fungi and their hosts that determines

36 the outcome of this symbiosis. 
37 Key words Dark septate endophytes (DSE), mycorrhizal dependency, mutualism-

38 parasitism continuum

40 Introduction

42 Dark septate endophytic (DSE) fungi are a common component of the microbial 43 communities colonizing healthy plant roots (Mandyam and Jumpponen 2005; 2008).

44 Although several studies have focused on DSE and documented their abundance in

45 different habitats, many aspects of their ecology remain unknown. Much of the present

46 understanding of DSE symbiosis, diversity and ecological significance is based on

47 limited number of taxa (Addy et al. 2005; Mandyam and Jumpponen 2005). Recent

48 studies from grasslands have provided valuable information about DSE including

49 estimates of their abundance, their temporal and seasonal variability, as well as their

50 community composition (Mandyam and Jumpponen 2008; Herrera et al. 2010; Mandyam 51 et al. 2010).

53 In the tallgrass prairie ecosystem, DSE fungi are a major component and colonize

54 a large proportion of the root system in mixed plant communities equaling colonization

55 by arbuscular mycorrhizal (AM) fungi (Mandyam and Jumpponen 2008). To identify the

56 dominant DSE fungi in this system, Mandyam et al. (2010) repeatedly isolated and

57 successfully resynthesized DSE formed by Periconia macrospinosa Lefevbre and

58 Johnson and Microdochium sp. expanding the list of potential DSE fungi. The abundance

59 of the DSE fungi is not limited to tallgrass prairies as indicated by the colonization of 
60 Bouteloua gracilis (Willd. ex Kunth) Lag. ex Griffiths across a broad geographical range

61 (Herrera et al. 2010). Bouteloua gracilis not only supports an abundance of DSE fungi

62 (Porras-Alfaro et al. 2007; Khidir et al. 2010), but seems to be colonized by novel DSE

63 communities with a large Pleosporalean component (Porras-Alfaro et al. 2008).

64

65 Despite the recent broad studies on the ecology and abundance of DSE fungi,

66 many aspects - including their host range - remain largely unknown. DSE fungi have

67 been proposed to possess a broad host range based on the number of hosts they can

68 colonize in laboratory experiments or on the number of plant species from which DSE

69 fungi have been isolated (Jumpponen and Trappe 1998). For example, Phialocephala

70 fortinii Wang and Wilcox colonizes at least eight plant species and has been isolated from

71 as many as 29 plant species (Jumpponen and Trappe 1998; Jumpponen 2001). Fernando

72 and Currah (1996) isolated Leptodontidium orchidicola Sigler and Currah from ten

73 species at a Canadian site. Similarly, a DSE isolate from Ranunculus adoeus A. Gray,

74 produced endophytic structures when inoculated onto Zea mays L. (Schadt et al. 2001).

75 Taken together, these observations support the hypothesis that DSE have a broad host

76 range, which has remained to be explicitly tested under controlled experimental

77 conditions.

79 Host responses to DSE fungi are uncertain and currently under debate

80 (Jumpponen 2001; Addy et al. 2005; Mandyam and Jumpponen 2005; Alberton et al.

81 2010; Newsham 2011). Recent meta-analyses of the limited number of available studies

82 have produced conflicting results. Alberton et al. (2010) concluded that, while host 
83 growth responses to DSE fungi were variable, they tended to be on average negative. In

84 contrast, broader and more detailed meta-analyses conducted by Newsham (2011), found

85 that DSE inoculation increased host biomass, particularly when inoculation was

86 conducted either in a system with no additional inorganic $\mathrm{N}$ or when majority of the $\mathrm{N}$

87 had been supplied in organic forms. These conflicting meta-analyses emphasize the

88 considerable variability in host responses to DSE fungi but also that, like arbuscular

89 mycorrhizas and ectomycorrhizas, the DSE symbioses may be context-dependent (Karst

90 et al. 2008; Hoeksema et al. 2010). In addition to the inter- and intraspecific variability of

91 the plants (Piculell et al. 2008; Karst et al. 2009) and fungi (Munkvold et al. 2004)

92 addressed here, the differences in host responses may be attributable to environmental

93 conditions and modulated by shade, drought, salinity and nutrient depletion (Johnson et

94 al. 1997; Kageyama et al. 2008; Rodriguez et al. 2008; Hoeksema et al. 2010).

95

96 In the present studies, we used controlled laboratory resyntheses to explore the

97 specificity and effects on host responses of two DSE fungi, P. macrospinosa and

98 Microdochium sp. commonly isolated from a native tallgrass prairie (Mandyam et al.

99 2010). We inoculated five native grasses and six forbs and included additional previously

100 published data for the grass Andropogon gerardii Vitman (Mandyam et al. 2010).

101 Specifically, we aimed to (1) microscopically confirm root colonization of the twelve

102 target plant species by four strains of two DSE fungi (three strains of $P$. macrospinosa

103 and one of Microdochium sp.) and (2) evaluate the effects of DSE colonization on host

104 biomass. Led by the results of these resyntheses, we validated our laboratory observations 
105 and tested hypotheses on whether or not the observed greater DSE colonization of grasses

106 in vitro could be confirmed in field-collected material.

\section{Materials and methods}

110 Site description

112 Fungal strains and plant materials were obtained from Konza Prairie Biological Research

113 Station (KPBS, $39^{\circ} 05^{\prime} \mathrm{N}, 96^{\circ} 35^{\prime} \mathrm{W}$ ), which represents a mesic native tallgrass prairie in

114 the Flint Hills of eastern Kansas, USA. This site spans 3,487 ha and has remained

115 undisturbed by agriculture. The vegetation is dominated by A. gerardii, Sorghastrum

116 nutans (L.) Nash., Schizachyrium scoparium (Michx.) Nash, and Panicum virgatum L.

117 (see Towne 2002 for a complete list of vascular plants at KPBS). The soil parent material

118 is chert-bearing limestone and the soil bulk density is $1.0 \mathrm{~g} / \mathrm{cm}^{3}$. January mean

119 temperature is $-3^{\circ} \mathrm{C}$ (range -9 to $3^{\circ} \mathrm{C}$ ) and the July mean is $27^{\circ} \mathrm{C}$ (range 20 to $33^{\circ} \mathrm{C}$ ).

120 Annual precipitation is $835 \mathrm{~mm}$, of which about $75 \%$ occurs in the growing season. For

121 the field survey of root colonization, samples were collected from two annually spring

122 burned lowlands and two infrequently (every 20 year burn) burned watersheds to account

123 for management and geographic variability in fungal colonization.

125 Resynthesis with native prairie plants 
127 One Microdochium sp. (KS0012) and three Periconia macrospinosa strains (KS0019,

128 KS0045 and KS0100) previously isolated and identified by Mandyam et al. (2010) from

129 KPBS were used for in vitro experiments. In these laboratory experiments, we tested the

130 fungal compatibility with native prairie plants by resynthesizing fungal structures

131 (microsclerotia and chlamydospores, Mandyam et al. 2010) indicative of the DSE

132 symbiosis. We analyzed a total of twelve native species (Table 1) for their in vitro

133 colonization and growth responses. Five grass species (B. gracilis, Elymus canadensis L.,

$134 P$. virgatum, S. scoparium, S. nutans) were selected for the resynthesis experiments. We

135 also include and re-analyze A. gerardii data published earlier (Mandyam et al. 2010) for

136 comparison with this broader selection of taxa. In addition to these six native grasses, we

137 selected six forbs (Asclepias syriaca L., Baptisia australis (L.) Br. ex Aiton, Echinacea

138 angustifolia DC, Dalea purpurea Vent, Helianthus maximilianii Schrad, Viola sp.). Grass

139 seeds (provided by Richard Wynia at the United States Department of Agriculture

140 Natural Resources Conservation Service) were surface sterilized in $70 \%$ alcohol for 30

141 min followed by $30 \%$ bleach for $20 \mathrm{~min}$. Forb seeds (W. Atlee Burpee and Co.

142 Warminster, Pennsylvania, USA) were sterilized in alcohol for $10 \mathrm{~min}$ followed by $30 \%$

143 bleach for $10 \mathrm{~min}$. Sterilized seeds were germinated on $1 / 10^{\text {th }}$ strength Murashige Skoog

144 (MS) medium (Sigma, Missouri, USA) for a week in a growth chamber under $12 \mathrm{~h}$ cycle

145 of light (ca. $250 \mu \mathrm{mol} / \mathrm{m}^{-2} \mathrm{~s}^{-1}$ PAR at $20^{\circ} \mathrm{C}$ ). Seeds of some plant species were repeatedly

146 contaminated by seed-borne fungal endophytes and due to the unavailability of a large

147 number of sterile seeds, some resynthesis experiments became unbalanced and some

148 fungal treatments were omitted (Fig. 1; Table 1). 
The resynthesis system was set up as described in Mandyam et al. (2010). In

151 brief, the system consisted of Petri plates with MS plant growth media and sealed with

152 parafilm. Germling roots were placed inside the plate so that the shoots grew outside

153 through a slit cut in both the lid and the plate. After seedling stabilization for four days, 6

$154 \mathrm{~mm}$ plugs cut from an actively growing margin of a colony on potato dextrose agar

155 (PDA) were used for inoculation and plates were incubated for six weeks. Fungus-free

156 controls were inoculated with similar sterile, fungus-free PDA plugs. Initially, each

157 treatment received 15 replicates and was incubated in the growth chamber under the

158 above conditions. Omission of contaminated experimental units led to unbalanced

159 experimental designs at harvest. Where possible, shoots of all 15 replicates and roots of

16010 replicates were harvested, dried at $50^{\circ} \mathrm{C}$, and their dry weight recorded. Roots from

161 the remaining five replicates were used for microscopic observation to confirm

162 colonization in the Periconia and Microdocchium treatments or absence of contamination

163 in the fungus-free controls. Total biomass and root:shoot ratio were calculated.

165 Confirmation of root colonization in resynthesis roots

167 Root samples from five replicates were used for screening presence/absence of DSE 168 structures. Microsclerotia and melanized hyphae were recorded in the Periconia 169 treatments, and chlamydospores in the Microdochium treatment (Mandyam et al. 2010).

170 Because most DSE structures are melanized, the roots were observed without staining.

171 The agar medium dried in some treatments with fast growing host species after six weeks 
172 of incubation. Removal of these root systems was difficult and estimation of the percent

173 root length colonized (\%RLC) omitted.

174

175 Plant responses to DSE colonization

176

177 To gain a better understanding of the relative host responses to DSE fungi, we modified

178 the 'mycorrhizal dependency', a metric occasionally used in determining plant

179 responsiveness to mycorrhizal symbiosis (Wilson and Hartnett 1998; Klironomos 2003).

180 Since use of the term 'dependency' for DSE symbiosis is likely inaccurate, we use

181 'responsiveness' (R) to describe DSE colonization as a means to assist in evaluating

182 variable plant growth responses:

183

184 If the median dry weight of inoculated treatment exceeded that in fungus-free 185 control, then

186

$R=[($ median dry weight of inoculated treatment - median dry weight of fungusfree control treatment)/ median dry weight of inoculated treatment]

If the median dry weight of fungus-free control treatment exceeded that in the 191 inoculated treatment, then

192 $R=[($ median dry weight of inoculated treatment - median dry weight of fungus194 free control treatment)/ median dry weight of fungus-free control treatment] 
196 Because our data were often skewed and non-normally distributed, we chose to use

197 median dry weights instead of means to estimate R. A great advantage of this metric is

198 that it normalizes the responses to inoculation treatments so that the observations are

199 distributed from -1 to 1 and can be tested for a null hypothesis of R equaling zero for no

200 response. This metric also simply illustrates the host responses to inoculation: values

201 greater than zero indicate positive responses, values lesser than zero negative responses.

203 Field sample collection from KPBS

205 To test the hypothesis that grasses are more heavily colonized by DSE fungi than forbs,

206 we analyzed fifteen species collected from KPBS (Table 1). Roots from up to eight

207 individuals of commonly-occurring grasses (A. gerardii, Bouteloua curtipendula

208 (Michx.) Torr., B. gracilis, Buchloe dactyloides (Nutt.) Engelm, Poa pratensis L., S.

209 scoparium, S. nutans) and forbs (Achillea millefolium L., Ambrosia artemisiifolia L.,

210 Artemesia ludoviciana Nutt., A. syriaca, Lespedeza capitata Michx., Plantago

211 patagonica Jacq., Sphaeralcea sp., Solidago missouriensis Nutt.) were randomly sampled

212 in late May and late July in 2004. Since no green plants for some of the early-season

213 forbs (e.g., P. patagonica) could be located or identified in the July sampling; or some

214 late season grasses (e.g., B. dactyloides, B. gracilis, B. curtipendula) and forbs (e.g., L.

215 capitata, S. missouriensis) be located or identified in the May sampling, the numbers of

216 species and samples varied across the samplings. Consequently, the colonization data

217 were analyzed separately for the two sampling occasions. The final, complete data

218 matrices consisted of 43 forb and 20 grass samples in May and 42 forb and 45 grass 
219 samples in May for a total of 150 samples. A plant shoot was collected to assure

220 sampling of correctly identified, attached roots. Roots were washed free of soil under

221 running tap water. Cleaned roots were transported to the laboratory for further

222 processing.

224 Staining and microscopy of field-collected roots

226 Roots adhering to the shoots were cut to $1 \mathrm{~cm}$ fragments and cleared by autoclaving (5

$227 \mathrm{~min} ; 121^{\circ} \mathrm{C} ; 15 \mathrm{psi}$ ) in $2.5 \%$ potassium hydroxide followed by several washes with water

228 and neutralization with acetic acid. To observe AM and DSE colonization in the sampled

229 roots, one random half of the cleared roots was immersed in Trypan blue (Philips and

230 Hayman 1970), another in Sudan IV (Barrow and Aaltonen 2001), and autoclaved for 4

231 min followed by several washes in water. The stained roots were allowed to destain in

232 acidic glycerol (500 ml glycerol, $450 \mathrm{ml} \mathrm{H}_{2} \mathrm{O}, 50 \mathrm{ml} \mathrm{HCl}$ ) overnight.

234 Colonization in the stained roots was estimated by magnified intersection method 235 (McGonigle et al. 1990) at 200× magnification for total colonized root length (\%RLC).

236 For each plant, ten randomly selected roots $(1 \mathrm{~cm})$ were used for quantification and AM

237 (i.e. presence of any AM structure - AM hyphae, vesicles, arbuscules, or coils) and DSE

238 (i.e. presence of any DSE structure - melanized septate hyphae and microsclerotia)

239 colonization in ten intersections per segment were recorded for a total of one hundred 240 intersections. 
242 Statistical analysis of resynthesis data

244 The mean total, shoot and root biomass plus root:shoot ratio of the inoculated treatments

245 for each plant species were compared to the controls using Dunnett's test in JMP

246 (Version 7.02, SAS Institute, Cary, North Carolina, U.S.A.). To equalize variances, the

247 biomasses and root:shoot ratios were log-transformed prior to analyses. The

248 responsiveness (R) was analyzed across the broad functional groupings (grasses vs. forbs)

249 using one-way ANOVA. Two-tailed Student's t-tests were used to test whether or not the

250 mean of $\mathrm{R}$ differed from zero for any one species. To account for the multiple

251 comparisons, Bonferroni-corrected, conservative values for significance are also provided

252 for these analyses.

253

254 Statistical analyses of AM and DSE colonization at Konza Prairie

255

256 DSE data were not normally distributed and variances were not homogeneous (Levene's

257 test: $P<0.05)$, whereas the AM data were normally distributed and the variances were

258 homogeneous. To correct for these violations of the assumptions for ANOVA, all \%RLC

259 values were transformed by arcsine of the square root and analyzed with ANOVA in

260 JMP. Pair-wise differences, when necessary, were determined by Tukey's Honestly

261 Significant Difference (HSD) with $\alpha=0.05$.

262

\section{Results}


265 Root colonization in the resynthesis study

267 All tested hosts were colonized by Microdochium sp. (KS0012) and two Periconia strains

268 (KS0045 and KS0100). The third Periconia strain (KS0019) colonized the hosts sparsely

269 indicating variability in the ability of Periconia strains to colonize hosts. Microdochium

270 sp. produced abundant chlamydospores in the cortex and root hairs in all tested plants.

271 Periconia (KS0045, KS0100) produced melanized microsclerotia and intercellular

272 hyphae in the grasses similar to those observed in A. gerardii resynthesis reported earlier

273 (Mandyam et al. 2010), but colonized the forbs only sparsely. Regrettably, we did not

274 record the \%RLC for the resynthesis studies and are unable to provide statistical

275 inference for these observations. One Periconia (KS0045) sporulated frequently on the

276 roots and produced melanized, septate conidiophores with black, echinulate spores

277 characteristic to the taxon.

279 Host responses to inoculation in the resynthesis study

281 Overall, grasses were more responsive to DSE inoculation treatments than forbs, 282 although two of the six analyzed native grasses ( $P$. virgatum and $S$. scoparium) were non283 responsive (Fig. 1). Compared to the fungus-free control, Periconia isolates KS0045 and 284 KS0100 increased A. gerardii shoot biomass by $79.8 \%$ and $110.3 \%$, respectively, 285 whereas the other two strains had no effect (Mandyam et al. 2010). Inoculation with all 286 four fungal strains increased B. gracilis total biomass $(221.8 \%-325.0 \%)$ and root 287 biomass $(291.1 \%$ - 460.5\%) compared to the fungus-free control; these biomass 
288 responses did not alter the root:shoot ratios. In E. canadensis, total biomass was

289 unaffected by three of the four strains, but was reduced $30.4 \%$ by Periconia strain

290 KS0045. In S. nutans, Microdochium sp. inoculation increased total (131.1\%), shoot

291 (92.5\%) and root (191.1\%) biomass and one of the three Periconia strains (KS0019)

292 increased total $(90.9 \%)$ and root $(135.7 \%)$ biomass. However, root:shoot ratio in none of

293 the treatments differed from the control. In contrast to grasses, none of the fungal

294 treatments affected any of the forbs (Fig. 1). The shoot and root weights as well as

295 root:shoot ratios were similar to those in controls across all inoculation treatments.

297 Plant responsiveness to DSE colonization

299 Overall, grasses mostly responded positively to DSE colonization, whereas forbs were 300 mostly unresponsive (Fig. 2; Table 2). However, there were no differences between the 301 grasses and forbs overall: R-values for forbs were not different from those for grasses, 302 regardless of whether the strains were analyzed separately $(\mathrm{F}<2.66 ; P>0.1472)$ or the 303 data combined $\left(\mathrm{F}_{1,42}=2.69 ; P=0.1086\right)$. Accordingly, these apparent differences were 304 driven by species identities rather than broad monocot vs. dicot groupings. For grasses, R 305 was greater than zero in sixteen of the 24 observed plant-fungus trials (Table 2). Based on 306 Bonferroni-corrected two-tailed Student's $t$-tests for hypothesis $\mathrm{H}_{0}: \mathrm{R}=0$ at $\alpha=0.05$,

307 two of the six grasses (B. gracilis, S. nutans; Fig. 2) responded positively inoculation, 308 whereas one responded negatively (E. canadensis; Fig. 2). Based on R, B. gracilis was 309 most responsive and $P$. virgatum was ranked last. In contrast to grasses, forbs tended to 310 be relatively unresponsive to inoculation: $\mathrm{R}$ was greater than zero for only eight of the 
311 nineteen successfully completed trials (Table 2). None of the six forbs had an R different

312 from zero (two-tailed Student's $t$-tests for $\mathrm{H}_{0}$ : $\mathrm{R}=0$ at $\alpha=0.05$ after Bonferroni

313 correction).

314

315 Endophyte colonization in field-collected grasses and forbs

317 To compare the colonization of native forbs and grasses by AM and DSE fungi, we

318 analyzed the two types of root-associated fungi separately in early growing season in

319 May and at peak growing season in July. The separate analyses were necessary because

320 the species compositions between the two sampling events differed. Overall, the

321 colonization tended to be highly variable and differed in only few of the fifteen species

322 (Fig. 3). However, in the early season sampling in May, AM colonization in forbs was

$32311.2 \%$ greater than in grasses $\left(\mathrm{F}_{1,63}=8.10 ; P=0.0058\right)$. In contrast to AM, DSE

324 colonization in May was $20.7 \%$ greater in grasses than in forbs $\left(F_{1,63}=6.97 ; P=\right.$

325 0.0107). However, it is of note that these differences are mainly driven by variability and

326 individual species, not by grass vs. forb differences. For example, two forbs (A. syriaca

327 and Sphaeralcea sp.) and the common C4 grass (S. scoparium) had consistently high AM

328 colonization that was greater than that of one forb (A. ludoviciana) and two grasses (A.

329 gerardii and S. nutans) (Fig. 3). In general, pairwise differences as indicated by Tukey's

330 HSD were few among the species analyzed in May (Fig. 3). To exemplify, two grasses

331 (S. scoparium and S. nutans) had significantly $(\alpha=0.05)$ greater DSE colonization than

332 Sphaeralcea sp. and A. gerardii, whereas the other species did not differ from any of 333 these. 
335 In July, additional plant species were sampled because their identification was

336 enabled by presence of reproductive parts that were absent in May. In this sampling,

337 grasses were $11.8 \%$ more heavily colonized by $\mathrm{AM}\left(\mathrm{F}_{1,86}=8.08 ; P=0.0056\right)$ and $34.6 \%$

338 more heavily colonized by DSE $\left(\mathrm{F}_{1,86}=39.28 ; P<0.0001\right)$ than forbs (Fig. 3). Similar to

339 the sampling in May, variability in AM colonization was high and differences between

340 the species few. Two grasses ( $P$. pratensis and $S$. scoparium) were more heavily

341 colonized than one grass (B. curtipendula) and three forbs (A. millefolium, A.

342 ludoviciana, and L. capitata). In contrast to AM, DSE colonization seemed more

343 distinctly higher in grasses. However, although the grass-forb differences among the

344 species were more frequent, these patterns are perhaps best characterized by high

345 variability within and between the species.

347 We also aimed to compare forb and grass colonization by AM and DSE. These 348 analyses indicated that forbs were colonized by AM to a greater degree than by DSE in 349 both May $\left(\mathrm{F}_{1,86}=89.32 ; P<0.0001\right)$ and July $\left(\mathrm{F}_{1,84}=37.03 ; P<0.0001\right)$. The

350 differences in AM and DSE colonization in grasses were less drastic. Grass colonization

351 by $\mathrm{AM}$ and DSE did not differ in May $\left(\mathrm{F}_{1,40}=1.73 ; P=0.1966\right)$ and $\mathrm{AM}$ colonization

352 was only marginally greater in July $\left(\mathrm{F}_{1,90}=4.36 ; P=0.0397\right)$. Overall, these field data

353 from early and peak growing season corroborate the results of our resynthesis study:

354 grasses have a greater DSE colonization than the forbs and that the grasses may show a 355 greater compatibility with the DSE fungi that forbs do. 
357 Our broad selection of native forbs also included a combination of annual $A$. 358 artemisiifolia and P. patagonica) and perennial (A. millefolium, A. ludoviciana, A.

359 syriaca, L. capitata, S. missouriensis) forbs. We omitted Sphaeralcea sp. from these 360 analyses because of the uncertainty whether it should be considered annual or perennial.

361 We observed no differences in AM colonization between the annual and perennial forbs

362 in May $\left(\mathrm{F}_{1,44}=0.24 ; P=0.6253\right)$ or July $\left(\mathrm{F}_{1,41}=0.001 ; P=0.9807\right)$. In contrast,

363 compared to annual forbs, perennial forbs were more heavily colonized by DSE in May

$364\left(\mathrm{~F}_{1,33}=8.14 ; P=0.0076\right)$, but these differences disappeared in the peak season sampling

365 in July $\left(\mathrm{F}_{1,22}=1.23 ; P=0.2951\right)$. As the DSE colonization seemed to decline overall,

366 these data suggest that the DSE may primarily inhabit aging tissues in forbs and

367 colonization of the annual tissues may coincide with aging of the root systems.

369 Discussion

371 Using combinations of host plants and DSE fungi native to tallgrass prairie in resynthesis

372 studies along with DSE colonization data in the field, this study confirms the "broad host

373 range' of DSE fungi. Interestingly, the data suggest that grasses may be more heavily

374 colonized by DSE and more responsive to DSE colonization than forbs. These

375 observations are congruent with Newsham's (2011) recent meta-analysis: although there

376 were no differences in the effect sizes between monocots and dicots in that study, the

377 highest effect sizes in biomass responses were observed for monocots. Additionally,

378 regardless of the broad plant groupings, our data confirm the outcomes of plant-DSE 
379 symbioses to fall within a range along the mutualism-parasitism continuum and seem to

380 include no pathogenic interactions.

An interesting but yet unanswered question is whether our results represent an in

383 vitro bias or artifact, even though the overall greater grass compatibility was observed

384 both under the field and in vitro conditions. Newsham (2011) concluded that hosts

385 respond more positively if no inorganic nitrogen is made available in the experiments and

386 when nitrogen is supplied in organic forms. At this point, further experiments are

387 necessary to empirically confirm the conclusions of those meta-analyses. However, our

388 choice to use MS medium with exclusively organic nitrogen sources may have affected

389 the host responses. If this were true and if inorganic nitrogen supply lead to lesser or

390 fewer positive host responses, then we would have underestimated the proportion of the

391 positive host responses. This underestimation may have been further exaggerated by our

392 use of conservative Bonferroni corrections in the analyses of host responsiveness (Fig. 2).

394 DSE host range

396 Broad host range of DSE fungi has been hypothesized, mostly based surveys of DSE 397 fungal colonization of different plant species (Jumpponen and Trappe 1998) and but also 398 based on the limited empirical data from resynthesis studies (Wilcox and Wang 1987;

399 O'Dell et al. 1993; Fernando and Currah 1996; Schadt et al. 2001). Similar DSE 400 colonization in different hosts such as by P. fortinii in Lupinus latifolius Agardh. and 401 Pinus contorta Dougl. (O'Dell et al. 1993), and by an unknown DSE fungus in $R$. adoeus 
402 and corn (Schadt et al. 2001) have suggested the broad host range of DSE. In this study,

403 we provide compelling evidence for a broad DSE host range using both resynthesis and

404 field assays of native tallgrass prairie plants. Our data show that native grasses and forbs

405 are colonized by DSE fungi, albeit to varying degrees. Microdochium sp. colonized all

406 hosts, whereas the colonization patterns of Periconia isolates were more variable: two

407 strains (KS0045 and KS0100) colonized all plant species producing intracellular

408 microsclerotia and intercellular hyphae, while one strain (KS0019) colonized hosts more

409 sparsely. The inclusion of representative DSE isolates suggests that screening a sizeable

410 number of host-DSE combinations may be necessary to draw meaningful conclusions

411 about the ability of DSE fungi to colonize various hosts.

412

413 Of the six native grasses, two responded positively to DSE inoculation, whereas

414 the forbs seemed less likely to benefit from DSE colonization. Based on these results and

415 on our anecdotal observations of more sparse colonization of forbs in the resynthesis

416 experiments, we propose that native tallgrass grasses are more compatible with DSE

417 fungi than co-occurring native forbs. To provide further evidence for the greater grass

418 colonization by DSE fungi, we sampled native hosts from the tallgrass prairie ecosystem

419 where the hosts and fungi naturally co-occur. The results of this field survey were similar

420 to our observations in the resynthesis experiments: DSE fungi colonized all native hosts

421 to some degree. More importantly, as predicted from our observations in the resynthesis

422 experiment, grasses on average hosted greater DSE colonization than forbs. Weishampel

423 and Bedford (2006), similarly, observed that the DSE colonization in monocots was

424 significantly greater than that in dicots. Furthermore, Khidir et al. (2010) evaluated the 
425 root-associated fungal communities of three co-occuring species - two grasses $(B$.

426 gracilis and Sporobolus cryptandrus) and Yucca glauca - and found that the grasses

427 shared a core group of root-associated fungi distinct from that in $Y$. glauca.

428

429 In addition to broad monocot vs. dicot differences on AM and/or DSE

430 colonization, we also observed some seasonal patterns. While the AM colonization in

431 forbs exceeded that in grasses in early season, grass AM colonization surpassed that of

432 forbs in the second sampling. In contrast, the DSE colonization was consistently higher in

433 grasses than in forbs, although the effect of including additional species is unclear.

434 Clearly, the plants are colonized to varying degrees by the DSE fungi as indicated by the

435 lower colonization of annual forbs in the early sampling. The decline in the overall forb

436 colonization suggests root senescence related seasonal dynamics in these systems and a

437 potential DSE function in root nutrient turnover.

439 DSE symbiosis: mutualism-parasitism continuum

441 In this study, host biomass was used to screen responses to DSE fungi under resynthesis

442 conditions. Host responses to DSE colonization were highly variable: inoculation either

443 increased, decreased or had no effect on the biomass or root:shoot ratio, indicating a

444 range of potential and variable interactions. It is notable that many observed responses

445 were neutral, whereas few were mutualistic and fewer yet were parasitic (Fig. 2). While it

446 has been hypothesized that mutualistic interactions are more frequently developed

447 between microbes and roots, only a fraction of root-associated fungi may interact 
448 positively with their hosts (Schulz and Boyle 2005; Kageyama et al. 2008). None of our

449 DSE isolates were pathogenic as all the tested plants appeared to be visibly healthy and

450 without any colonization of the root vascular cylinder. These observations suggest that

451 disease and tissue re-organization are exceptions in these endophyte interactions; perhaps

452 an imbalance in symbiosis (Schulz et al. 1999; Kogel et al. 2006). Redman et al. (2001)

453 suggested that a fungal isolate may be pathogenic in one host, mutualistic in another or

454 colonize some plants as a commensal. Even in mycorrhizal symbioses, neutral and

455 negative responses are commonly encountered (Johnson et al. 1997; Karst et al. 2008).

456 Whether interactions between the plant and its fungal endophytes are balanced

457 (mutualism or commensalism) or imbalanced (parasitism or pathogenicity) depends on

458 the fungal and plant genotypes, plant physiology, developmental stages of the partners,

459 and nutrient availability or other environmental factors (Schulz et al. 1999; Redman et al.

460 2001; Schulz and Boyle 2005; Kogel et al. 2006; Tanaka et al. 2006; Newsham 2011).

462 According to Schulz and Boyle (2005), the plant-endophyte interactions fall 463 within the symbiotic continuum, precluding the assignment of a particular life-history 464 strategy to a given endophyte. The outcomes of plant-endophyte interactions depend on a 465 'balance of antagonisms' and the phenotypic plasticity can stem from various factors 466 affecting the continuum (see above) as indicated by the DSE isolates that exhibited 467 negative or neutral effects on some hosts but conferring positive responses in others (e.g., 468 Periconia strain 10045 in E. canadensis and in B. gracilis). Interestingly, Rodriguez and 469 Redman (2008) suggest that changing life-history strategies in endophytes may signify 
470 evolutionary transitions or that the fungi have achieved a greater ecological flexibility

471 ensuring optimal growth and reproduction in different hosts.

472

\section{Conclusions}

474

475 To our knowledge this is the first study to broadly characterize interactions between DSE

476 isolates, grasses and forbs native to a tallgrass prairie ecosystem. The results support our

477 initial hypotheses that the native DSE fungi possess a broad host range. However, the

478 combination of laboratory resyntheses and microscopic analyses of field-collected

479 materials indicates that the DSE fungi colonize forbs to a lesser degree than they colonize

480 native grasses. However, high temporal, intra-, and interspecific variability preclude

481 explicit statements indicating that DSE colonization in any grass would exceed that in

482 any forb. DSE effects on host growth were variable and represented responses along the

483 mutualism-parasitism continuum. Based on our results and other published reports, the

484 outcome of plant-endophyte symbiosis seems to depend on the host species, endophyte

485 taxa or strains, their genetic makeup, extent of fungal colonization, and experimental 486 conditions.

488 Acknowledgements

490 This work was supported in part by NSF DEB-0344838 (to AJ). Konza Prairie Biological 491 Research Station (KPBS) maintained the field sites and was supported by National

492 Science Foundation Long Term Ecological Research (LTER) program. Chad Fox 
493 completed the microscopic analyses as a part of Konza Prairie LTER "Research

494 Experiences for Undergraduates" program. Richard Wynia at the United States

495 Department of Agriculture Natural Resources Conservation service provided some of the

496 native seeds for the described studies. Authors thank Justin Trowbridge for assistance in

497 acquiring the field-collected materials.

498

499 References

500

501 Addy HD, Piercey MM, Currah RS (2005) Microfungal endophytes in roots. Canadian

502 Journal of Botany 83:1-13. doi: 10.1139/B04-171

503 Alberton O, Kuyper TW, Summerbell RC (2010) Dark septate root endophytic fungi

504 increase growth of Scots pine seedlings under elevated $\mathrm{CO}_{2}$ through enhanced nitrogen

505 use efficiency. Plant Soil 328:459-470. doi: 10.1007/s11104-009-0125-8

506 Barrow JR, Aaltonen RE (2001) Evaluation of the internal colonization of Atriplex

507 canescens (Pursh) Nutt. roots by dark septate fungi and the influence of host

508 physiological activity. Mycorrhiza 11:199-205

509 Fernando AA, Currah RS (1996) A comparative study of the effects of the root

510 endophytes Leptodontidium orchidicola and Phialocephala fortinii (Fungi Imperfecti) on

511 the growth of some subalpine plants in culture. Canadian Journal of Botany 74:1071-

$512 \quad 1078$ 
513 Herrera J, Khidir HH, Eudy DM, Porras-Alfaro A, Natvig DO, Sinsabaugh RL (2010)

514 Shifting fungal endophyte communities colonize Bouteloua gracilis: effect of host tissue

515 and geographical distribution. Mycologia 102:1012-1026. doi: 10.3852/09-264

516 Hoeksema JD, Chaudhary VB, Gehring CA, Johnson NC, Karst J, Koide RT, Pringle A,

517 Zabinski C, Bever JD, Moore JC, Wilson GWT, Klironomos JN, Umbanhowar J (2010)

518 A meta-analysis of context-dependency in plant response to inoculation with mycorrhizal

519 fungi. Ecol Lett 13:394-407. doi: 10.1111/j.1461-0248.2009.01430.x

520 Johnson NC, Graham JH, Smith FA (1997) Functioning of mycorrhizal associations

521 along the mutualism-parasitism continuum. New Phytol 135:575-586

522 Jumpponen A (2001) Dark septate endophytes - are they mycorrhizal? Mycorrhiza

$523 \quad 11: 207-211$

524 Jumpponen A, Trappe JM (1998) Dark septate endophytes: a review of facultative

525 biotrophic root-colonizing fungi. New Phytol 140:295-310

526 Kageyama SA, Mandyam KG, Jumpponen A (2008) Diversity, function and potential

527 applications of the root-associated endophytes. In: Varma A (ed) Mycorrhiza - state of

528 the art, genetics and molecular biology, eco-function, biotechnology, ecophysiology,

529 structure and systemetics. Springer-Verlag, Berlin, pp. 29-59

530 Karst J, Jones MD, Turkington R (2009) Ectomycorrhizal colonization and intraspecific

531 variation in growth responses of lodgepole pine. Plant Ecol 200:161-165. doi:

$532 \quad 10.1007 / \mathrm{s} 11258-008-9443-9$ 
533 Karst J, Marczak L, Jones MD, Turkington R (2008) The mutualism-parasitism

534 continuum in ectomycorrhizas: A quantitative assessment using meta-analysis. Ecology

$535 \quad 89: 1032-1042$

536 Khidir HH, Eudy DM, Porras-Alfaro A, Herrera J, Natvig DO, Sinsabaugh RL (2010) A

537 general suite of fungal endophytes dominate the roots of two dominant grasses in a

538 semiarid grassland. J Arid Environ 74:35-42. doi: 10.1016/j.jaridenv.2009.07.014

539 Klironomos JN (2003) Variation in plant response to native and exotic arbuscular

540 mycorrhizal fungi. Ecology 84:2292-2301

541 Kogel K, Franken P, Hueckelhoven R (2006) Endophyte or parasite - what decides? Curr

542 Opin Plant Biol 9:358-363. doi: 10.1016/j.pbi.2006.05.001

543 Mandyam K, Jumpponen A (2005) Seeking the elusive function of the root-colonising

544 dark septate endophytic fungi. Stud Mycol :173-189

545 Mandyam K, Jumpponen A (2008) Seasonal and temporal dynamics of arbuscular

546 mycorrhizal and dark septate endophytic fungi in a tallgrass prairie ecosystem are

547 minimally affected by nitrogen enrichment. Mycorrhiza 18:145-155. doi:

$548 \quad 10.1007 / \mathrm{s} 00572-008-0165-6$

549 Mandyam K, Loughin T, Jumpponen A (2010) Isolation and morphological and

550 metabolic characterization of common endophytes in annually burned tallgrass prairie.

551 Mycologia 102:813-821. doi: 10.3852/09-212

552 Mcgonigle TP, Miller MH, Evans DG, Fairchild GL, Swan JA (1990) A new method

553 which gives an objective measure of colonization of roots by vesicular arbuscular

554 mycorrhizal fungi. New Phytol 115:495-501 
555 Munkvold L, Kjøller R, Vestberg M, Rosendahl S, Jakobsen I (2004) High functional

556 diversity within species of arbuscular mycorrhizal fungi. New Phytol 164:357-364. doi:

$557 \quad 10.1111 / j .1469-8137.2004 .01169 . x$

558 Newsham KK (2011) A meta-analysis of plant responses to dark septate root endophytes.

559 New Phytol 10.1111/j.1469-8137.2010.03611.x

560 O'Dell TE, Massicotte HB, Trappe JM (1993) Root colonization of Lupinus latifolius

561 Agardh and Pinus contorta Dougl by Phialocephala fortinii Wang and Wilcox. New

562 Phytol 124:93-100

563 Philips JM, Hayman DA (1970) Improved procedures for clearing and staining parasitic

564 and vesicular-arbuscular mycorrhizal fungi for rapid assessment of infection.

565 Transactions of the British Mycological Society 55:158-161

566 Piculell BJ, Hoeksema JD, Thompson JN (2008) Interactions of biotic and abiotic

567 environmental factors in an ectomycorrhizal symbiosis, and the potential for selection

568 mosaics. BMC Biology 6:23. doi: 10.1186/1741-7007-6-23

569 Porras-Alfaro A, Herrera J, Natvig DO, Sinsabaugh RL (2007) Effect of long-term

570 nitrogen fertilization on mycorrhizal fungi associated with a dominant grass in a semiarid

571 grassland. Plant Soil 296:65-75. doi: 10.1007/s11104-007-9290-9

572 Porras-Alfaro A, Herrera J, Sinsabaugh RL, Odenbach KJ, Lowrey T, Natvig DO (2008)

573 Novel root fungal consortium associated with a dominant desert grass. Appl Environ

574 Microbiol 74:2805-2813. doi: 10.1128/AEM.02769-07

575 Redman RS, Dunigan DD, Rodriguez RJ (2001) Fungal symbiosis from mutualism to

576 parasitism: who controls the outcome, host or invader? New Phytol 151:705-716 
577 Rodriguez R, Redman R (2008) More than 400 million years of evolution and some 578 plants still can't make it on their own: plant stress tolerance via fungal symbiosis. J Exp

579 Bot 59:1109-1114. doi: 10.1093/jxb/erm342

580 Rodriguez RJ, Henson J, Van Volkenburgh E, Hoy M, Wright L, Beckwith F, Kim Y,

581 Redman RS (2008) Stress tolerance in plants via habitat-adapted symbiosis. ISME

582 Journal 2:404-416. doi: 10.1038/ismej.2007.106

583 Schadt CW, Mullen RB, Schmidt SK (2001) Isolation and phylogenetic identification of

584 a dark-septate fungus associated with the alpine plant Ranunculus adoneus. New Phytol

$585 \quad 150: 747-755$

586 Schulz B, Boyle C (2005) The endophytic continuum. Mycol Res 109:661-686. doi:

$587 \quad 10.1017 / \mathrm{S} 095375620500273 \mathrm{X}$

588 Schulz B, Rommert AK, Dammann U, Aust HJ, Strack D (1999) The endophyte-host

589 interaction: a balanced antagonism? Mycol Res 103:1275-1283

590 Tanaka A, Christensen MJ, Takemoto D, Park P, Scott B (2006) Reactive oxygen species

591 play a role in regulating a fungus-perennial ryegrass mutualistic interaction. Plant Cell

592 18:1052-1066. doi: 10.1105/tpc. 105.039263

593 Towne EG (2002) Vascular plants of Konza Prairie Biological Station: an annotated

594 checklist of species in a Kansas tallgrass prairie. Sida 20:269-294

595 Weishampel PA, Bedford BL (2006) Wetland dicots and monocots differ in colonization

596 by arbuscular mycorrhizal fungi and dark septate endophytes. Mycorrhiza 16:495-502.

597 doi: 10.1007/s00572-006-0064-7 
598 Wilcox HE, Wang CJK (1987) Ectomycorrhizal and ectendomycorrhizal associations of

599 Phialophora finlandia with Pinus resinosa, Picea rubens, and Betula alleghaniensis.

600 Canadian Journal of Forest Research 17:976-990

601 Wilson GWT, Hartnett DC (1998) Interspecific variation in plant responses to

602 mycorrhizal colonization in tallgrass prairie. Am J Bot 85:1732-1738

603 


\section{Figure legends}

606 Fig. 1 Host responses (dry weight $\mathrm{mg}$; mean \pm 1 standard deviation) to five inoculation

607 treatments (fungus-free control, Microdochium sp. (strain KS10012) and Periconia

608 macrospinosa (strains KS10019, KS10045, and KS10100). Complete host binomials are

609 listed in Table 1 and grasses are underlined for clarity. Note that some fungal treatments

610 were omitted for species that had limited seed availability and/or carried seed-borne

611 contaminants. Shoot biomass above the $\mathrm{x}$-axis; root biomass below $\mathrm{x}$-axis. Asterisks on

612 the top of, next to the shoot, and next to the root biomass values indicate treatment

613 difference in total, shoot, root biomasses from the control based on Dunnett's test at $\alpha=$

614 0.05. There were no differences in root:shoot ratios.

616 Fig. 2 Host responsiveness (R; mean \pm 1 standard deviation) to inoculation with four

617 strains of DSE fungi. Complete host binomials are listed in Table 1 and grasses are 618 underlined for clarity. Responsiveness metric $\mathrm{R}$ was modified from that described in

619 Klironomos (2003). The symbols indicate significant two-tailed Student's $t$-tests for $\mathrm{H}_{0}$ :

$620 \mathrm{R}=0$ at $\alpha=0.05$ with (cross) and without (asterisk) the conservative Bonferroni 621 correction.

623 Fig. 3 Colonization (\% root length; mean \pm 1 standard deviation) of native forbs and 624 grasses (underlined) by dark arbuscular mycorrhizal (AM) and septate endophytic (DSE) 625 fungi in field-collected roots from Konza Prairie Biological Station. ANOVA table for 626 species effect is provided in the inset. The dashed lines identify the grand mean across all 
627 forbs or grasses sampled for each of the two (May, July) sampling occasions. Mean AM 628 colonization of forbs exceeded that of grasses in May; in all other comparisons grass 629 colonization exceeded that of the forbs. Letters on top identify significant differences of 630 values transformed by arcsine of the square root based on Tukey's Honestly Significant 631 Difference (HSD) with $\alpha=0.05$. 
Table 1 List of plant species used for testing host range of DSE fungi. Numbers indicate the total number of experimental units included in the field and in vitro resynhesis studies. The numbers for the field study identify number of samples in May and July.

\begin{tabular}{|c|c|c|c|c|}
\hline \multirow[t]{2}{*}{ Family } & \multirow[t]{2}{*}{ Species } & \multicolumn{2}{|c|}{ Field study ${ }^{\mathrm{a}}$} & \multirow[t]{2}{*}{ Resynthesis $^{\mathrm{a}}$} \\
\hline & & May & July & \\
\hline \multicolumn{5}{|c|}{ Asclepiadaceae } \\
\hline & Asclepias syriaca $\left(\mathrm{C}_{3}\right)$ & 7 & 6 & 16 \\
\hline \multicolumn{5}{|c|}{ Asteraceae } \\
\hline & Achillea millefolium $\left(\mathrm{C}_{3}\right)$ & 8 & 6 & N/A \\
\hline & Ambrosia artemesiifolia $\left(\mathrm{C}_{3}\right)$ & 8 & 8 & N/A \\
\hline & Artemesia ludoviciana $\left(\mathrm{C}_{3}\right)$ & 3 & 8 & N/A \\
\hline & Echinacea angustifolia $\left(\mathrm{C}_{3}\right)$ & N/A & N/A & 27 \\
\hline & Helianthus maximilianii $\left(\mathrm{C}_{3}\right)$ & N/A & N/A & 31 \\
\hline & Solidago missouriensis $\left(\mathrm{C}_{3}\right)$ & N/A & 8 & N/A \\
\hline \multicolumn{5}{|c|}{ Fabaceae } \\
\hline & Babtisia australis $\left(\mathrm{C}_{3}\right)$ & N/A & N/A & 16 \\
\hline & Dalea purpurea $\left(\mathrm{C}_{3}\right)$ & N/A & N/A & 56 \\
\hline & Lespedeza capitata $\left(\mathrm{C}_{3}\right)$ & N/A & 6 & N/A \\
\hline \multicolumn{5}{|c|}{ Malvaceae } \\
\hline \multicolumn{5}{|c|}{ Plantaginaceae } \\
\hline & Plantago patagonica $\left(\mathrm{C}_{3}\right)$ & 8 & N/A & N/A \\
\hline \multicolumn{5}{|c|}{ Poaceae } \\
\hline & $\begin{array}{l}\text { Andropogon gerardii }\left(\mathrm{C}_{4}\right)^{2} \\
\text { Bouteloua curtipendula }\left(\mathrm{C}_{4}\right)\end{array}$ & $\begin{array}{l}3 \\
\text { N/A }\end{array}$ & 8 & $\begin{array}{l}59 \\
\text { N/A }\end{array}$ \\
\hline & Bouteloua gracilis $\left(\mathrm{C}_{4}\right)$ & N/A & 5 & 36 \\
\hline & Buchloe dactyloides $\left(\mathrm{C}_{4}\right)$ & N/A & 5 & N/A \\
\hline & Elymus canadensis $\left(\mathrm{C}_{3}\right)$ & N/A & N/A & 72 \\
\hline & Panicum virgatum $\left(\mathrm{C}_{4}\right)$ & N/A & N/A & 67 \\
\hline & Poa pratensis $\left(\mathrm{C}_{3}\right)$ & 6 & 4 & N/A \\
\hline & Schizachyrium scoparium $\left(\mathrm{C}_{4}\right)$ & 5 & 8 & 72 \\
\hline & Sorgastrum nutans $\left(\mathrm{C}_{4}\right)$ & 6 & 8 & 57 \\
\hline viorace & Viola sp. $\left(\mathrm{C}_{3}\right)$ & N/A & N/A & 21 \\
\hline
\end{tabular}

${ }^{a}$ N/A plants were not available for the study component

${ }^{\mathrm{b}}$ data from (Mandyam et al. 2010) 
1 Table 2 Plant response (R) to inoculation by four strains of DSE fungi. N/A = missing 2 data.

\begin{tabular}{llllll}
\hline Plant species & $\begin{array}{l}\text { Microdochium } \\
\text { sp. } \\
\text { KS0012 }\end{array}$ & $\begin{array}{l}\text { Periconia } \\
\text { macrospinosa } \\
\text { KS0019 }\end{array}$ & $\begin{array}{l}\text { Periconia } \\
\text { macrospinosa } \\
\text { KS0045 }\end{array}$ & $\begin{array}{l}\text { Periconia } \\
\text { macrospinosa } \\
\text { KS0100 }\end{array}$ & $\begin{array}{l}\text { Mean } \\
\text { response }\end{array}$ \\
\hline $\begin{array}{l}\text { Grasses } \\
\begin{array}{l}\text { Andropogon } \\
\text { gerardii }\end{array}\end{array}$ & 0.55 & & & & \\
$\begin{array}{l}\text { Bouteloua } \\
\text { gracilis }\end{array}$ & 0.84 & 0.05 & 0.56 & 0.60 & 0.44 \\
$\begin{array}{l}\text { Elymus } \\
\text { canadensis }\end{array}$ & -0.29 & 0.84 & 0.79 & 0.84 & 0.77 \\
$\begin{array}{l}\text { Panicum } \\
\text { virgatum }\end{array}$ & -0.14 & -0.36 & -0.43 & -0.33 & -0.35 \\
$\begin{array}{l}\text { Schizachyrium } \\
\text { scoparium }\end{array}$ & 0.38 & -0.48 & -0.41 & -0.43 & -0.37 \\
$\begin{array}{l}\text { Sorgastrum } \\
\text { nutans }\end{array}$ & 0.67 & 0.36 & 0.14 & 0.46 & 0.34 \\
\hline
\end{tabular}

\section{Forbs}

Asclepias

N/A

N/A

0.13

0.04

$-0.09$

syriaca

Baptisia

N/A

0.02

0.05

$-0.22$

$-0.15$

australis

Dalea

0.06

0.19

0.20

0.32

0.19

purpurea

Echinacea

$-0.17$

0.46

0.39

0.25

0.23

angustifolia

Helianthus

$-0.25$

$-0.33$

$-0.09$

N/A

$-0.15$

maximilianii

Viola sp.

N/A

$-0.14$

$-0.14$

0.13

$-0.15$ 
Click here to download high resolution image
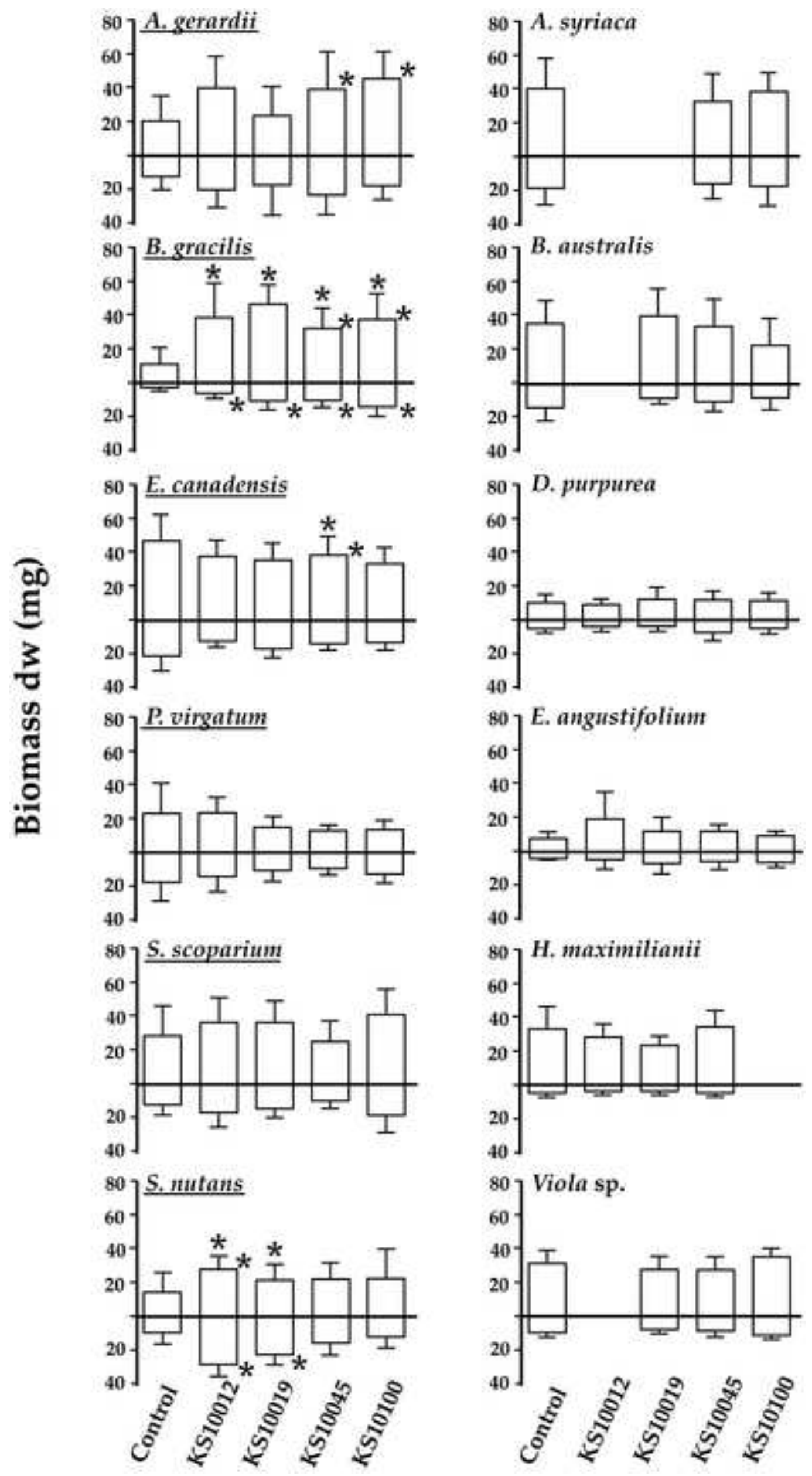


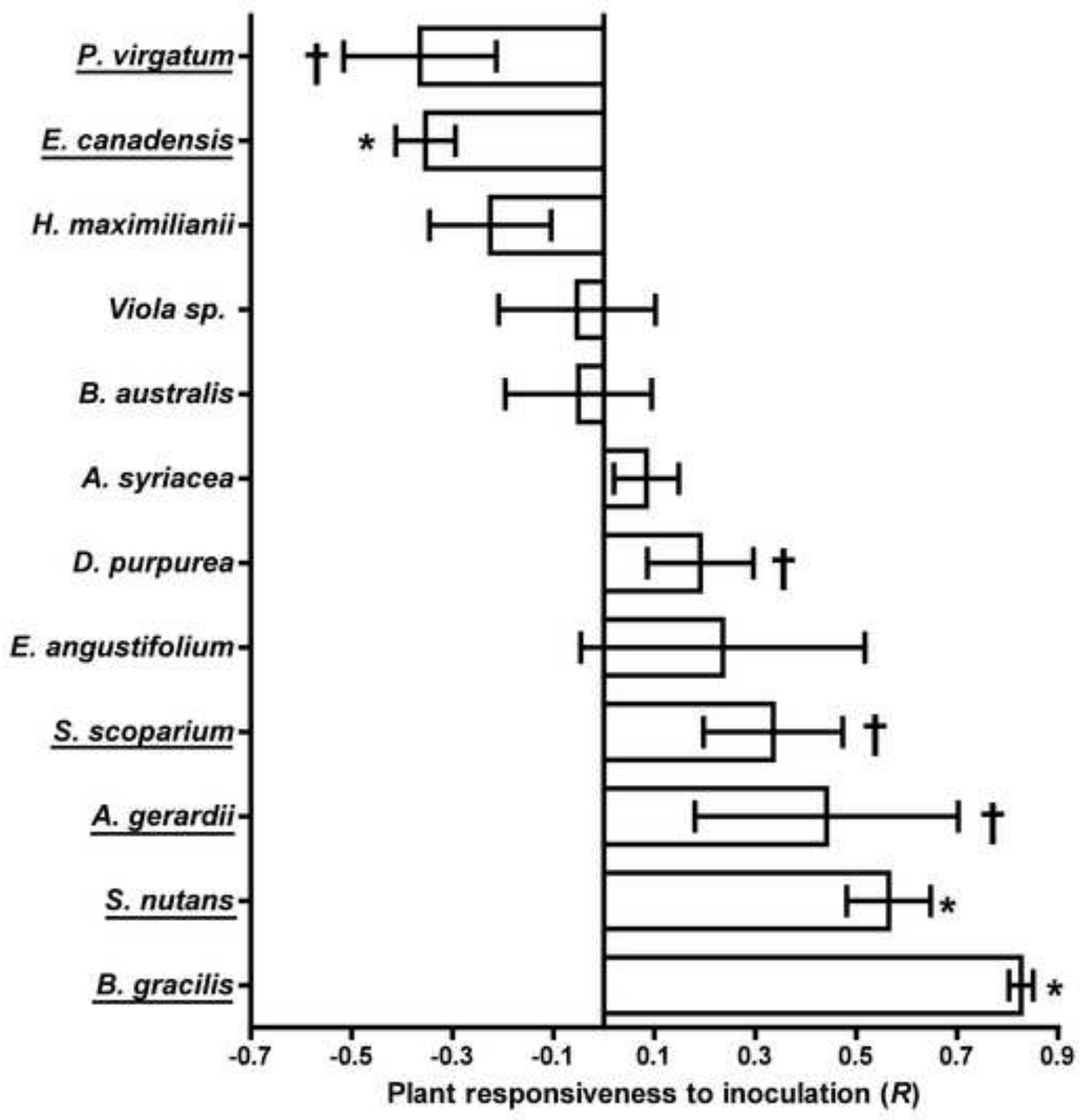



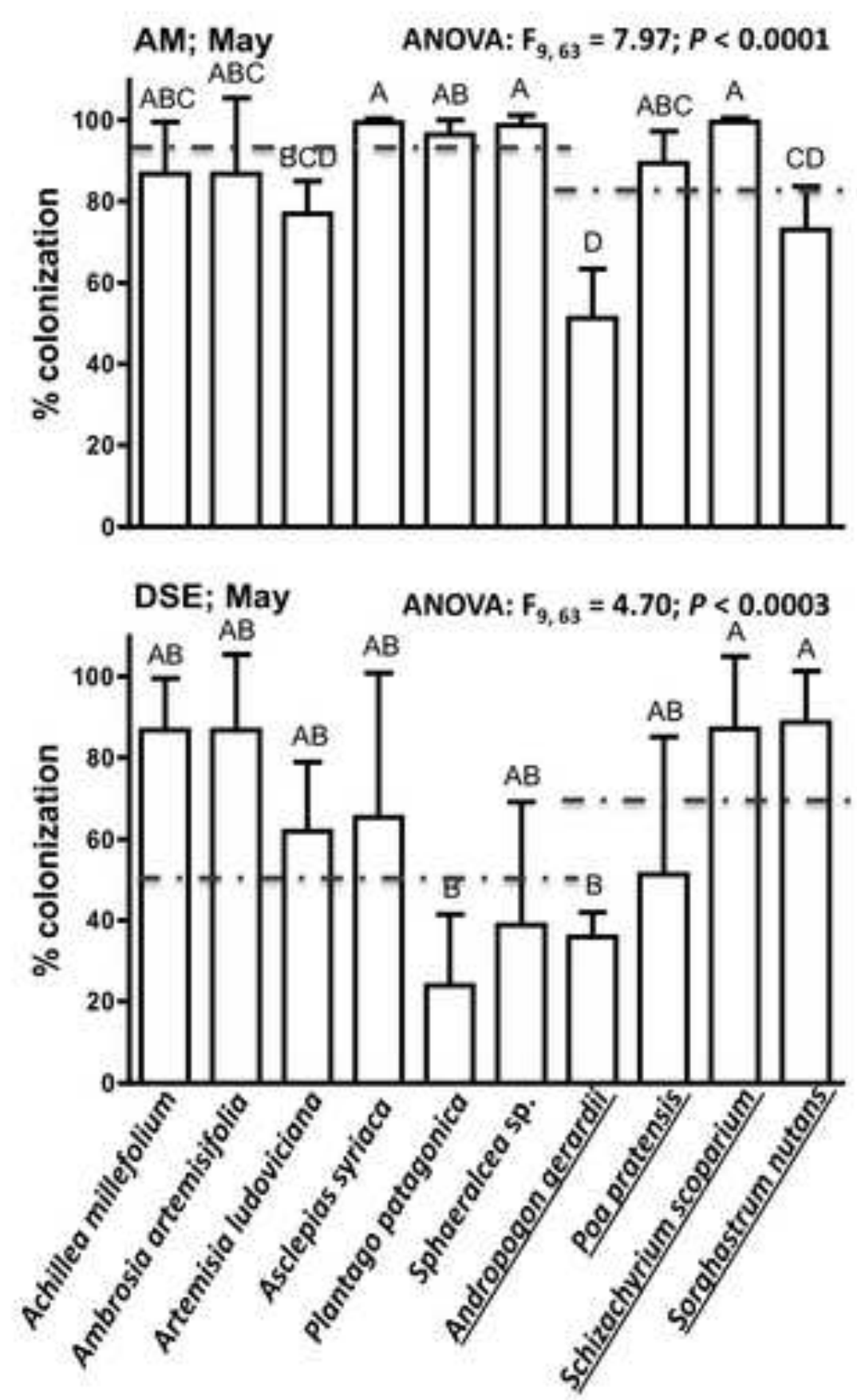
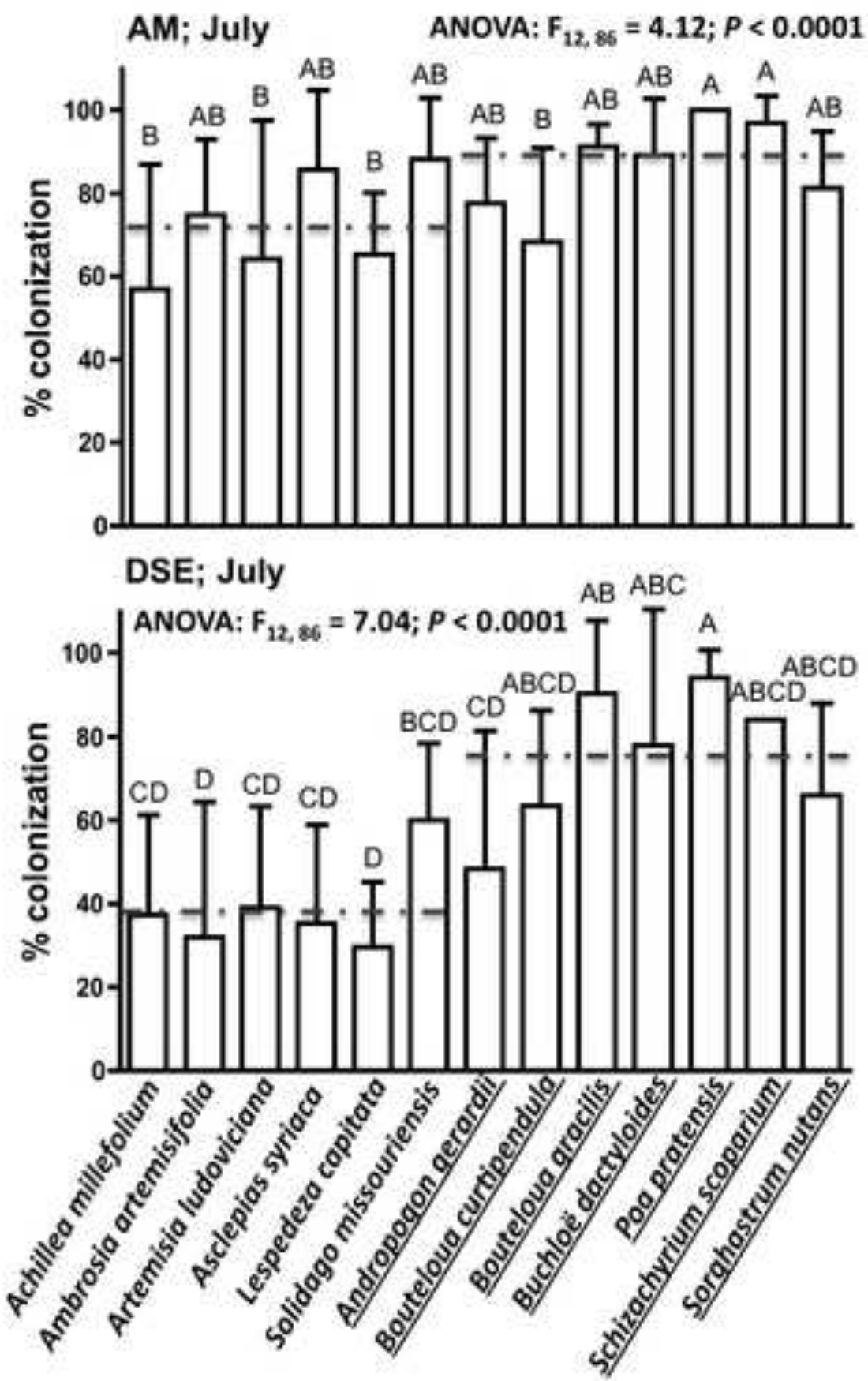